San Jose State University

SJSU ScholarWorks

Master's Projects

Master's Theses and Graduate Research

Fall 2015

\title{
Author recognition using Locality Sensitive Hashing \& Alergia (Stochastic Finite Automata)
}

Prashanth Sandela

San Jose State University

Follow this and additional works at: https://scholarworks.sjsu.edu/etd_projects

Part of the Computer Sciences Commons

\section{Recommended Citation}

Sandela, Prashanth, "Author recognition using Locality Sensitive Hashing \& Alergia (Stochastic Finite Automata)" (2015). Master's Projects. 447.

DOI: https://doi.org/10.31979/etd.qm3z-9rhx

https://scholarworks.sjsu.edu/etd_projects/447

This Master's Project is brought to you for free and open access by the Master's Theses and Graduate Research at SJSU ScholarWorks. It has been accepted for inclusion in Master's Projects by an authorized administrator of SJSU ScholarWorks. For more information, please contact scholarworks@sjsu.edu. 


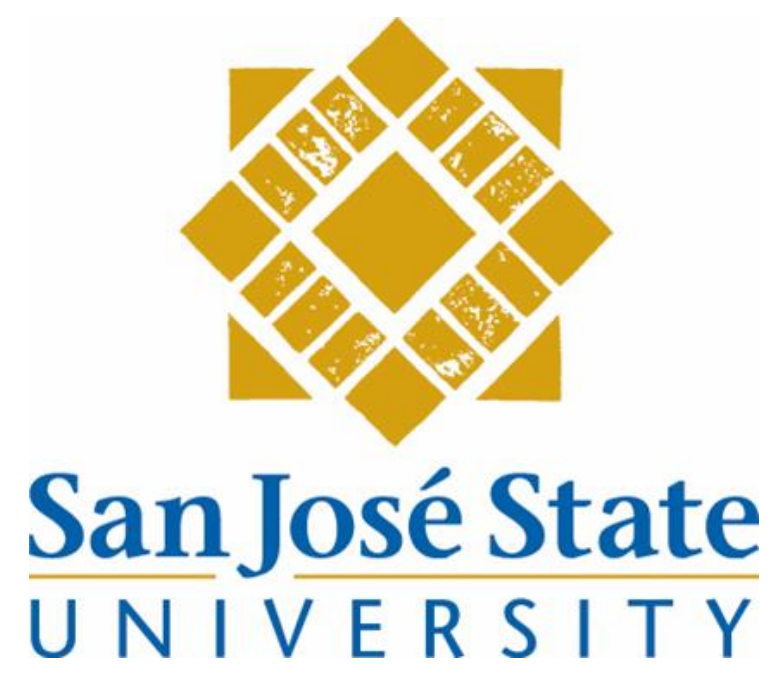

Author recognition using Locality Sensitive Hashing \& Alergia (Stochastic Finite Automata)

\author{
A Thesis \\ Presented to The Faculty of the Department of Computer Science \\ San José State University
}

In Partial Fulfillment

Of the Requirements for the Degree

Master of Science

By

Prashanth Sandela

December 2015 
(C) 2015

Prashanth Sandela

\section{ALL RIGHTS RESERVED}




\title{
San Jose State University
}

The Designated Thesis Committee Approves the Thesis Titled Author recognition using Locality Sensitive Hashing \& Alergia (Stochastic Finite Automata)

\author{
By \\ Prashanth Sandela \\ APPROVED FOR THE DEPARTMENT OF COMPUTER SCIENCE \\ SAN JOSÉ STATE UNIVERSITY
}

December 2015

Dr. T. Y. Lin, Department of Computer Science

Date

Dr. Thomas Austin, Department of Computer Science

Date

Mr. Karthik Rajagopalan, Lead Data Engineer at Target

Date 


\section{ABSTRACT}

In today's world data grows very fast. It is difficult to answer questions like 1) Is the content completely written by this author, 2) Did he get few sentences or pages from another author, 3) Is there any way to identify actual author. There are many plagiarism software's available in the market which identify duplicate content. It doesn't understand writing pattern involved. There is always a necessity to make an effort to find the original author. Locality sensitive hashing is one such standard for applying hashing to recognize authors writing pattern. 


\section{ACKOWLEDGEMENTS}

I want to take to thank everyone who has contributed towards completion of my project. The journey towards the end of the project was fruitful, exciting and great learning procedure. Experience gained from the project will help me solve many problems in the future.

I would like to thank Dr. T.Y.Lin, my project advisor, for giving me this wonderful project and helping me to successfully complete this project and get a great insight about real time challenges and problems. Thanks for your attention and support. I would like to thank my committee members, Dr. Thomas Austin and Karthik Rajagopalan for support and patience.

I would like to thank Computer Science department for providing me opportunity and with the necessary material. I would like to thank everyone who has helped and guided me to successfully complete this project. 


\section{Contents}

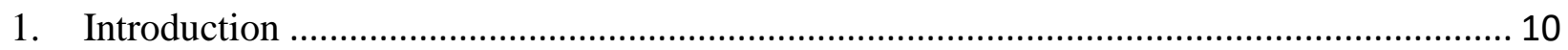

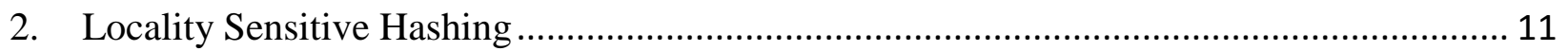

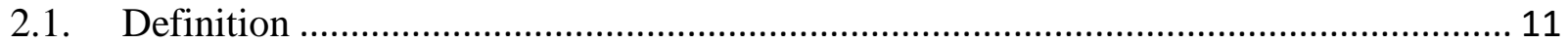

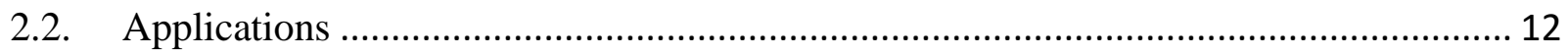

2.3. Hashing algorithms following Locality Sensitive Hashing......................................... 12

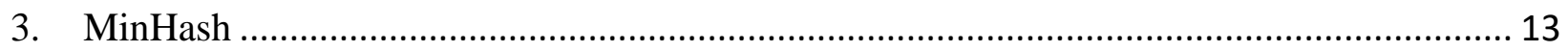

3.1. Jaccard Similarity and minimum hash values .......................................................... 13

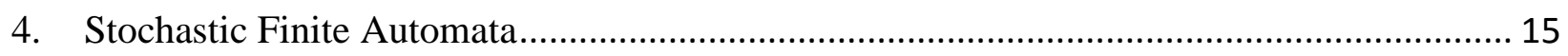

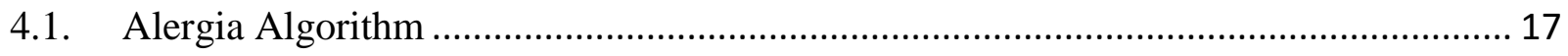

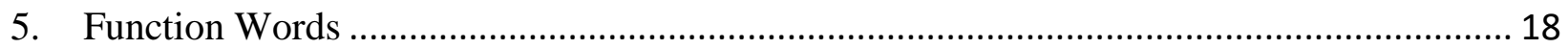

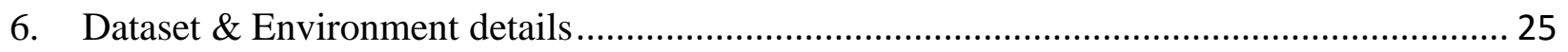

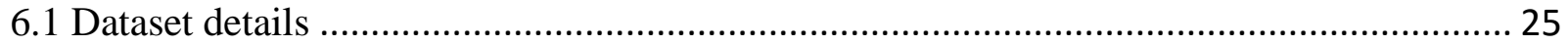

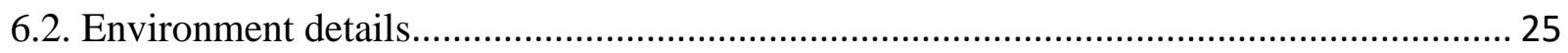

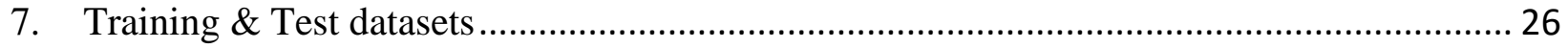

8. Applying MinHash (Jaccard Similarity) for author recognition ......................................... 28

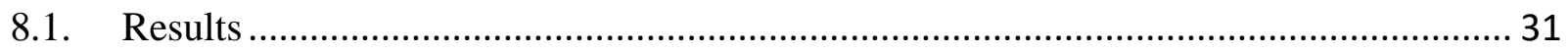

9. Applying Stochastic Finite Automata using Alergia Algorithm to recognize author ............ 35 


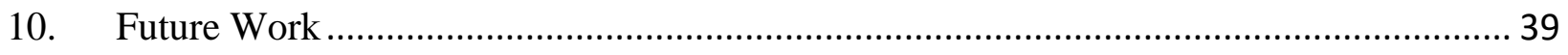

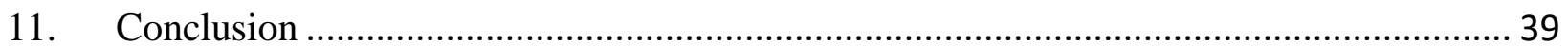

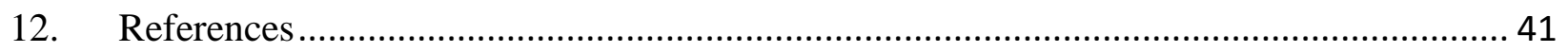




\section{$\underline{\text { List of Tables }}$}

1. Differences between Deterministic Finite Automata \& Non Deterministic Finite Automata 16

2. List of function words

3. Results for Jaccard Similarity for Test Case 1

4. Results for Jaccard Similarity for Test Case 2

5. Results for Jaccard Similarity for Test Case 3

6. Representing Alergia results for Test Case 1

7. Representing Alergia results for Test Case 2

8. Representing Alergia results for Test Case 3 


\section{$\underline{\text { List of Figures }}$}

1. Document A 28

2. Document B 28

3. Identifying common statements 29

4. Set of three documents 30 


\section{Introduction}

There are many authors in today's world. This count keeps growing day by day. It is estimated that there are more than 20 Billion authors. Anyone who writes some content which may be a book or blog post or a blog comment is considered as an author.

With the growing authors and post or books, it is being increasingly difficult to track authors identity. Even now there are millions of documents without a recognized author. It is important to know the true identity of the author so that you might want to read more of his documents. With the increasing access to internet, it is very easy to duplicate particular content and hide the real author. There are many plagiarism software's available in the market but they can say if the content is original, they don't have the capability to identify author. There is really a necessity to have a model which tells the author. Our model should be able to identify author of the document.

The main basis to identify the pattern of the author is very different from other types of mining. For many types of data mining, we eliminate most of the stop words and special characters to make a sense out of data. For recognizing authors writing pattern we have to consider stop words and special characters, helps identify sentences. This can be achieved using many hashing algorithms

of Locality Sensitive Hashing ${ }^{[1][2]}$ and using Stochastic Finite Automata Technique (Alergia Algorithm). 


\section{Locality Sensitive Hashing}

Locality Sensitive Hashing ${ }^{[2]}$ reduces dimensionality of high-dimensional data. It has a hashing method which has high probability of mapping similar items to same buckets i.e., the total number of input items are much higher than the no. of buckets. This hashing is different from conventional hash functions and cryptographic hash functions coz it aims to maximize the possibility of likeitems-collision. This Hashing is commonly used in data clustering and nearest neighbor search.

\subsection{Definition}

Locality Sensitive Hashing family ${ }^{[5][6][7]} \mathbf{F}$ is defined for metric space $\mathbf{M}$, an approximate factor $\mathbf{C}$ and a threshold $\mathbf{R}$.

$$
M=(M, d), R>0, C>1
$$

The $\mathbf{F}$ is a family of functions $\mathbf{h}: \mathbf{M}=>\mathbf{S}$ which maps to the elements of $\mathbf{M}$ to a bucket $\mathbf{s} \in \mathbf{S}$.

Locality Sensitive Hashing family satisfies below conditions for $\mathbf{p}, \mathbf{q} \in \mathbf{M}$, using $\mathbf{h} \mathbf{\epsilon}$

- If $\mathbf{d}(\mathbf{p}, \mathbf{q}) \leq \mathbf{R}$, then $\mathbf{h}(\mathbf{q})$ equals $\mathbf{h}(\mathbf{p})$ i.e.., $\mathbf{p}$ and $\mathbf{q}$ collides with probability $>\mathbf{P}_{\mathbf{1}}$

- If $\mathbf{d}(\mathbf{p}, \mathbf{q}) \geq \mathbf{C R}$, then $\mathbf{h}(\mathbf{q})$ equals $\mathbf{h}(\mathbf{p})$ i.e.., $\mathbf{p}$ and $\mathbf{q}$ collides with probability $<\mathbf{P}_{2}$

A family when $\mathbf{P}_{\mathbf{1}}>\mathbf{P}_{\mathbf{2}}$. Then this $\mathbf{F}$ is called $\left(\mathbf{R}, \mathbf{c R}, \mathbf{P}_{1}, \mathbf{P}_{\mathbf{2}}\right)$

LSH is defined with universe $\mathrm{U}$ with a similarity function $\mathbb{U} \mathbf{X} \mathbf{U} \rightarrow[\mathbf{0}, \mathbf{1}]$.

This locality sensitive hashing scheme is a family of $\mathbf{H}$ which are paired with probability distribution $\mathbf{D}$, such that a $\mathrm{h} \mathbf{\epsilon} \mathrm{H}$ chosen according to $\mathbf{D}$.

$$
\operatorname{Pr}_{\mathbf{h} \in \mathrm{H}}[\mathbf{h}(\mathbf{a})=\mathbf{h}(\mathbf{b})]=\boldsymbol{( a , b )} \text { for any } \mathbf{a}, \mathbf{b} \in \mathbf{U}
$$




\subsection{Applications}

- Image similarity identification

- Hierarchical clustering

- Audio similarity identification

- Near-duplicate detection

- Genome-wide association study

- Audio fingerprint

- Nearest neighbor search

- Digital video fingerprinting

2.3. Hashing algorithms following Locality Sensitive Hashing

- Min-Hashing

- Sim-Hashing

- Hamming Similarity

- Angle Similarity 


\section{MinHash}

MinHash ${ }^{[16]}$ hashing scheme is a technique to estimating similarity between two sets. MinHash is also known as Min-Wise Independent permutations of Locality Sensitive Hashing. Andrei Broder invented MinHash scheme. In the early stages of search engine, this scheme was used in AltaVista search engine to detecting duplicate web pages. MinHash has its application in largest-scale clustering documents or problems.

\subsection{Jaccard Similarity and minimum hash values}

The Jaccard similarity coefficient ${ }^{[16]}$ is also called Jaccard index. This is used to indicate similarity of two sets.

Let us consider 2 sets $\mathrm{A}$ and $\mathrm{B}$.

$\mathrm{A} \cap \mathrm{B}=>$ intersection of 2 sets

A $U B \Rightarrow$ union of 2 sets.

Jaccard similarity coefficient can be defined as ratio of intersection and union of sets.

$$
J(A, B)=\frac{|A \cap B|}{|A \cup B|} .
$$

The value of Jaccard similarity coefficient is strictly between 0 and 1 .

$\mathrm{J}(\mathrm{A}, \mathrm{B})=0$ if the sets are disjoint, (No common elements)

$=1$ if the sets are equal

$<=1$ if the sets have relatively more members in common. 
The goal of MinHash is to quickly estimate $\mathrm{J}(\mathrm{A}, \mathrm{B})$ without performing any operations like union and intersection.

Let us assume a hash function $\mathbf{h}$. Let this map $\mathrm{X}$ and $\mathrm{Y}$ to distinct integers. Set $\mathrm{Z}$ defines $h_{\min }(Z)$ to be least member of $\mathrm{Z}$ with regards to $\mathrm{h}$ i.e.., the member $\mathrm{n}$ of $\mathrm{Z}$ with least value of $\mathrm{h}(\mathrm{x})$. If $\mathrm{h}_{\min }$ is applied to $\mathrm{X}$ and $\mathrm{Y}$, it can be observed that they get same values when elements of (X U Y) with a minimum hash value which resides in $(\mathrm{X} \cap \mathrm{Y})$.

$\operatorname{Pr}\left[h_{\min }(X)=h_{\min }(Y)\right]=J(X, Y)$, This equation implies that this follows Locality Sensitive Hashing.

This implies that the probability of $h_{\min }(X)=h_{\min }(Y)$ is TRUE $==$ similarity $J(X, Y)$, provided sets $X$ and $Y$ are randomly choosen. So, if $r$ is the random variable then

$$
h_{\min }(X)=h_{\min }(Y) \text { and zero otherwise, }
$$

then $r$ is unbiased estimator of $J(X, Y) . r$ can be used as estimator for Jaccard Similarity coz it has too high variance, the value is always either zero or one. The overall overview of MinHash scheme is to reduce this variance by calculating the average of several variables constructed in the same way. 


\section{Stochastic Finite Automata}

In computer science and mathematics, the Probabilistic Automation $(\mathrm{P})$ is generalization of non-deterministic finite automaton. This also includes converting probability of any given transition into a transition function. This turns into a stochastic or transition matrix. So, the probabilistic automaton generalizes concept of sub-shift of finite type or Markov chain. Thus, these languages are known as stochastic languages.

Finite automaton $\mathrm{A}=(\mathrm{S}, \mathrm{P}, \mathrm{i}, \delta, \mathrm{T})$ where

P: finite input alphabet

$\delta:$ is a function: $\delta: \mathrm{S} \times \mathrm{A}->\mathrm{S}$. This is known as transition function.

$\mathrm{S}$ : is a finite set known as set of states.

$\mathrm{T}$ : is subset of $\mathrm{S}$ known as terminal state.

Non-Deterministic Finite Automata(NDFA):

This type of automata has multiple acceptance state at any instance of time. Transition from one state to another state is possible in many number of states. 
Deterministic Finite Automata Vs Non-Deterministic Finite Automata ${ }^{[13]}$ :

\begin{tabular}{|l|l|}
\hline Deterministic Finite Automata & Non Deterministic Finite Automata \\
\hline Characterized as a 5 tuple state: & C $, \mathrm{S}, \mathrm{A}, \mathrm{S}, \mathrm{T}, \mathrm{S}, \mathrm{F}, \mathrm{F}\rangle$ \\
\hline $\mathrm{S}$ is the set of states & S is the set of states \\
\hline A is the alphabet & A is the alphabet \\
\hline T is the transition function: & T is the transition function: \\
\hline S $x$ A $\rightarrow$ S & S $x(A)\{\varepsilon\}) \rightarrow P S$ \\
\hline$S_{0}$ is the initial state & So is the initial state \\
\hline F is the set of accepting states. & F is the set of accepting states. \\
\hline
\end{tabular}

Table 1: Differences between Deterministic Finite Automata \& Non Deterministic Finite Automata 


\subsection{Alergia Algorithm}

Alergia Algorithm is can be determined as Stochastic Finite State Transducer (SFST) ${ }^{[14][15]}$. We use Alergia Algorithm for our author pattern recognition. Below is the algorithm.

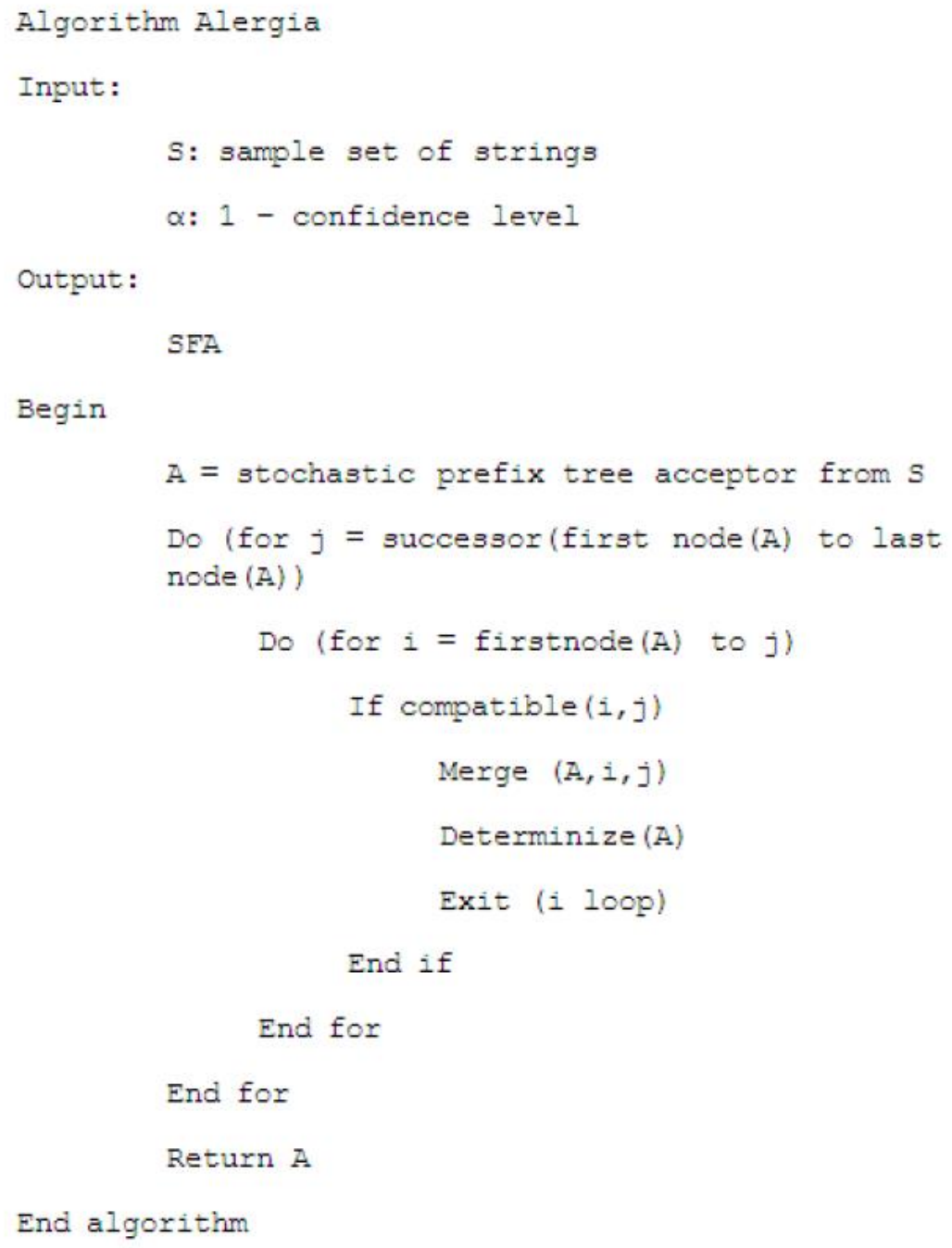




\section{Function Words}

Function words ${ }^{[8]}$ are words that have lexical meaning, which serves to express grammatical relationships with different words in a sentence, or specify mood or attitude of a speaker. In some cases, function words might also have ambiguous meaning.

In the phase of the project, the functional words are stop words. There are 261 function words which have been categorized into 7 different types by Stanford. These serve the purpose for differentiating among various stop words and for easy computation. Below is the list of function words with their equivalent weight.

Table 2: List of function words

\begin{tabular}{|c|l|c|}
\hline Sl. No & Function Word & Category \\
\hline 1 & a & 3 \\
\hline 2 & able & 1 \\
\hline 3 & aboard & 4 \\
\hline 4 & about & 4 \\
\hline 5 & above & 4 \\
\hline 6 & absent & 4 \\
\hline 7 & according & 4 \\
\hline 8 & accordingly & 2 \\
\hline 9 & across & 4 \\
\hline 10 & after & 4 \\
\hline 11 & against & 4 \\
\hline 12 & ahead & 4 \\
\hline
\end{tabular}

\begin{tabular}{|c|l|c|}
\hline Sl. No & Function Word & Category \\
\hline 131 & must & 1 \\
\hline 132 & my & 3 \\
\hline 133 & myself & 5 \\
\hline 134 & near & 4 \\
\hline 135 & need & 1 \\
\hline 136 & neither & 3 \\
\hline 137 & nevertheless & 2 \\
\hline 138 & next & 4 \\
\hline 139 & no & 3 \\
\hline 140 & no_one & 5 \\
\hline 141 & nobody & 5 \\
\hline 142 & none & 5 \\
\hline
\end{tabular}




\begin{tabular}{|c|c|c|}
\hline 13 & albeit & 2 \\
\hline 14 & all & 6 \\
\hline 15 & along & 4 \\
\hline 16 & alongside & 4 \\
\hline 17 & although & 2 \\
\hline 18 & amid & 4 \\
\hline 19 & amidst & 4 \\
\hline 20 & among & 4 \\
\hline 21 & amongst & 4 \\
\hline 22 & amount & 6 \\
\hline 23 & an & 3 \\
\hline 24 & and & 2 \\
\hline 25 & another & 3 \\
\hline 26 & anti & 4 \\
\hline 27 & any & 3 \\
\hline 28 & anybody & 5 \\
\hline 29 & anyone & 5 \\
\hline 30 & anything & 5 \\
\hline 31 & around & 4 \\
\hline 32 & as & 2 \\
\hline 33 & aside & 4 \\
\hline 34 & astraddle & 4 \\
\hline 35 & astride & 4 \\
\hline
\end{tabular}

\begin{tabular}{|c|c|c|}
\hline 143 & nor & 2 \\
\hline 144 & nothing & 5 \\
\hline 145 & notwithstanding & 4 \\
\hline 146 & number & 6 \\
\hline 147 & numbers & 6 \\
\hline 148 & of & 4 \\
\hline 149 & off & 4 \\
\hline 150 & on & 4 \\
\hline 151 & once & 2 \\
\hline 152 & one & 5 \\
\hline 153 & onto & 4 \\
\hline 154 & opposite & 4 \\
\hline 155 & or & 2 \\
\hline 156 & other & 3 \\
\hline 157 & ought & 1 \\
\hline 158 & our & 3 \\
\hline 159 & ours & 5 \\
\hline 160 & ourselves & 5 \\
\hline 161 & out & 4 \\
\hline 162 & outside & 4 \\
\hline 163 & over & 4 \\
\hline 164 & part & 6 \\
\hline 165 & past & 4 \\
\hline
\end{tabular}




\begin{tabular}{|c|c|c|}
\hline 36 & at & 4 \\
\hline 37 & away & 4 \\
\hline 38 & bar & 4 \\
\hline 39 & barring & 4 \\
\hline 40 & be & 1 \\
\hline 41 & am & 1 \\
\hline 42 & are & 1 \\
\hline 43 & is & 1 \\
\hline 44 & was & 1 \\
\hline 45 & were & 1 \\
\hline 46 & because & 2 \\
\hline 47 & before & 4 \\
\hline 48 & behind & 4 \\
\hline 49 & below & 4 \\
\hline 50 & beneath & 4 \\
\hline 51 & beside & 4 \\
\hline 52 & besides & 4 \\
\hline 53 & between & 4 \\
\hline 54 & beyond & 4 \\
\hline 55 & bit & 6 \\
\hline 56 & both & 3 \\
\hline 57 & but & 2 \\
\hline 58 & by & 4 \\
\hline
\end{tabular}

\begin{tabular}{|c|c|c|}
\hline 166 & pending & 4 \\
\hline 167 & per & 4 \\
\hline 168 & pertaining & 4 \\
\hline 169 & place & 4 \\
\hline 170 & plenty & 6 \\
\hline 171 & plethora & 6 \\
\hline 172 & plus & 4 \\
\hline 173 & quantities & 6 \\
\hline 174 & quantity & 6 \\
\hline 175 & regarding & 4 \\
\hline 176 & remainder & 6 \\
\hline 177 & respecting & 4 \\
\hline 178 & rest & 6 \\
\hline 179 & round & 4 \\
\hline 180 & save & 4 \\
\hline 181 & saving & 4 \\
\hline 182 & several & 6 \\
\hline 183 & shall & 1 \\
\hline 184 & she & 5 \\
\hline 185 & should & 1 \\
\hline 186 & similar & 4 \\
\hline 187 & since & 4 \\
\hline 188 & so & 2 \\
\hline
\end{tabular}




\begin{tabular}{|c|c|c|}
\hline 59 & can & 1 \\
\hline 60 & certain & 6 \\
\hline 61 & circa & 4 \\
\hline 62 & close & 4 \\
\hline 63 & concerning & 4 \\
\hline 64 & consequently & 2 \\
\hline 65 & considering & 4 \\
\hline 66 & could & 1 \\
\hline 67 & couple & 6 \\
\hline 68 & dare & 1 \\
\hline 69 & despite & 4 \\
\hline 70 & down & 4 \\
\hline 71 & due & 4 \\
\hline 72 & during & 4 \\
\hline 73 & each & 3 \\
\hline 74 & either & 3 \\
\hline 75 & enough & 6 \\
\hline 76 & every & 3 \\
\hline 77 & everybody & 5 \\
\hline 78 & everyone & 5 \\
\hline 79 & everything & 5 \\
\hline 80 & except & 4 \\
\hline 81 & excepting & 4 \\
\hline
\end{tabular}

\begin{tabular}{|c|c|c|}
\hline 189 & some & 6 \\
\hline 190 & somebody & 5 \\
\hline 191 & someone & 5 \\
\hline 192 & something & 5 \\
\hline 193 & spite & 4 \\
\hline 194 & such & 5 \\
\hline 195 & than & 2 \\
\hline 196 & that & 2 \\
\hline 197 & the & 3 \\
\hline 198 & their & 3 \\
\hline 199 & theirs & 5 \\
\hline 200 & them & 5 \\
\hline 201 & themselves & 5 \\
\hline 202 & then & 2 \\
\hline 203 & therefore & 2 \\
\hline 204 & these & 3 \\
\hline 205 & they & 5 \\
\hline 206 & this & 3 \\
\hline 207 & those & 3 \\
\hline 208 & though & 2 \\
\hline 209 & through & 4 \\
\hline 210 & throughout & 4 \\
\hline 211 & thru & 4 \\
\hline
\end{tabular}




\begin{tabular}{|c|c|c|}
\hline 82 & excluding & 4 \\
\hline 83 & failing & 4 \\
\hline 84 & few & 6 \\
\hline 85 & fewer & 6 \\
\hline 86 & following & 4 \\
\hline 87 & for & 4 \\
\hline 88 & from & 4 \\
\hline 89 & front & 4 \\
\hline 90 & have & 1 \\
\hline 91 & has & 1 \\
\hline 92 & had & 1 \\
\hline 93 & he & 5 \\
\hline 94 & heaps & 6 \\
\hline 95 & hence & 2 \\
\hline 96 & her & 5 \\
\hline 97 & hers & 5 \\
\hline 98 & herself & 5 \\
\hline 99 & him & 5 \\
\hline 100 & himself & 5 \\
\hline 101 & his & 5 \\
\hline 102 & however & 2 \\
\hline 103 & $\mathrm{i}$ & 5 \\
\hline 104 & if & 2 \\
\hline
\end{tabular}

\begin{tabular}{|c|c|c|}
\hline 212 & thus & 2 \\
\hline 213 & till & 4 \\
\hline 214 & to & 4 \\
\hline 215 & tons & 6 \\
\hline 216 & top & 4 \\
\hline 217 & toward & 4 \\
\hline 218 & towards & 4 \\
\hline 219 & under & 4 \\
\hline 220 & underneath & 4 \\
\hline 221 & unless & 2 \\
\hline 222 & unlike & 4 \\
\hline 223 & until & 4 \\
\hline 224 & unto & 4 \\
\hline 225 & up & 4 \\
\hline 226 & upon & 4 \\
\hline 227 & us & 5 \\
\hline 228 & various & 6 \\
\hline 229 & versus & 4 \\
\hline 230 & via & 4 \\
\hline 231 & wanting & 4 \\
\hline 232 & we & 5 \\
\hline 233 & what & 5 \\
\hline 234 & whatever & 2 \\
\hline
\end{tabular}




\begin{tabular}{|c|c|c|}
\hline 105 & in & 4 \\
\hline 106 & including & 4 \\
\hline 107 & inside & 4 \\
\hline 108 & instead & 4 \\
\hline 109 & into & 4 \\
\hline 110 & it & 5 \\
\hline 111 & its & 5 \\
\hline 112 & itself & 5 \\
\hline 113 & lack & 6 \\
\hline 114 & less & 6 \\
\hline 115 & like & 4 \\
\hline 116 & little & 6 \\
\hline 117 & loads & 6 \\
\hline 118 & lots & 6 \\
\hline 119 & majority & 6 \\
\hline 120 & many & 6 \\
\hline 121 & masses & 6 \\
\hline 122 & may & 1 \\
\hline 123 & me & 5 \\
\hline 124 & might & 1 \\
\hline 125 & mine & 5 \\
\hline 126 & minority & 6 \\
\hline 127 & minus & 4 \\
\hline
\end{tabular}

\begin{tabular}{|c|c|c|}
\hline 235 & when & 2 \\
\hline 236 & whenever & 2 \\
\hline 237 & where & 2 \\
\hline 238 & whereas & 2 \\
\hline 239 & wherever & 2 \\
\hline 240 & whether & 2 \\
\hline 241 & which & 5 \\
\hline 242 & whichever & 2 \\
\hline 243 & while & 2 \\
\hline 244 & whilst & 2 \\
\hline 245 & who & 5 \\
\hline 246 & whoever & 2 \\
\hline 247 & whole & 6 \\
\hline 248 & whom & 5 \\
\hline 249 & whomever & 2 \\
\hline 250 & whose & 5 \\
\hline 251 & will & 1 \\
\hline 252 & with & 4 \\
\hline 253 & within & 4 \\
\hline 254 & without & 4 \\
\hline 255 & would & 1 \\
\hline 256 & yet & 2 \\
\hline 257 & you & 5 \\
\hline
\end{tabular}




\begin{tabular}{|c|l|c|}
128 & more & 6 \\
\hline 129 & most & 6 \\
\hline 130 & much & 6 \\
\hline
\end{tabular}

\begin{tabular}{|c|l|c|}
\hline 258 & your & 3 \\
\hline 259 & yours & 5 \\
\hline 260 & yourself & 5 \\
\hline 261 & yourselves & 5 \\
\hline
\end{tabular}

Below are the sentences with the application of function words

Examples:

Sentence: "Function words ${ }^{[8]}$ are words that have lexical meaning, which serves to express grammatical relationships with different words in a sentence, or specify mood or attitude of a speaker"

Function word sentence: are that have little or have but instead to with other within a Word category: 121621244434123243

Now the complete sentence has been converted to list of integers 12162124443412324

3. This list is used to identify authors pattern. 


\section{Dataset \& Environment details}

\subsection{Dataset details}

The dataset I have chosen for this project is Novels written by different authors. These novels are available on internet and can be obtained for free for educational purpose. The size of the document gives a cutting edge to form clusters authors. Below are few numerical details about the dataset.

- Avg. no of lines in a document: $~ 9 \mathrm{k}$

- Number of documents: 33

- Number of authors: 27

6.2. Environment details

- Processor: i7 $4^{\text {th }}$ Gen $2.40 \mathrm{Ghz}$

- RAM: 8GB

- Operating System: Windows 10

- Programming language: JAVA 64-bit

- Graphical Memory: 2GB Intel HD 4700 Graphics, 2GB NVIDIA 655M 


\section{Training \& Test datasets}

Documents considered in the for training the model.

1. Adam Smith - An Inquiry into the nature.txt

2. Alexandre Dumas - The Count of Monte Cristo.txt

3. Arthur Conan Doyle -The Adventures of Sherlock Holmes.txt

4. Bram Stoker - Dracula.txt

5. Canan Doyle - A Study in Scarlet.txt

6. Charles Dickens - David Copperfield.txt

7. Charlotte Bronte - Jane Eyre.txt

8. Daniel Defoe - Robinson Crusoe.txt

9. Dante Alighieri - The Divine Comedy.txt

10. Edgar Rice Burroughs - A Princess of Mars.txt

11. Elliott Whithey - The Pirate Shark.txt

12. Frank Baum - The Wonderful Wizard of Oz.txt

13. Friedrich Nietzsche - Beyond Good and Evil.txt

14. Gabriel Garcia Marquez - Years of Solitude.txt

15. Harrison Williams - Legends of Loudoun.txt

16. J.K. Rowling - Harry Potter And the Order OF Phoenix.txt

17. J.K. Rowling - Harry Potter and Sorcerer's Stone.txt

18. Herbert George Wells - The War of the Worlds.txt

19. Herman Melville - Moby Dick.txt

20. Herman See; - A Son of the City.txt 
21. Hermann Hesse- Siddhartha.txt

22. James Joyce - Dubliners.txt

23. James Matthew Barrie - Peter Pan.txt

24. Jane Austen - Emma.txt

25. John Milton - Paradise Lost.txt

26. Jonathan Swift - Gulivers Traveles.txt

27. Joseph Conrad - Heart of Darkness.txt

28. Jules Verne - Around the World in Days.txt

29. Julia Ward Howe - From the Oak to the Olive.txt

30. Leo Tolstoy - War and Peace.txt

\section{Test document:}

1. J.K. Rowling - Harry Potter and the Order OF Phoenix.txt 


\section{Applying Jaccard Similarity for author recognition}

Considering two documents A and B documents written by same author. All the documents have different statements. Each document will have its statements. Below are the diagrams representing documents $\mathrm{A}$ and $\mathrm{B}$.

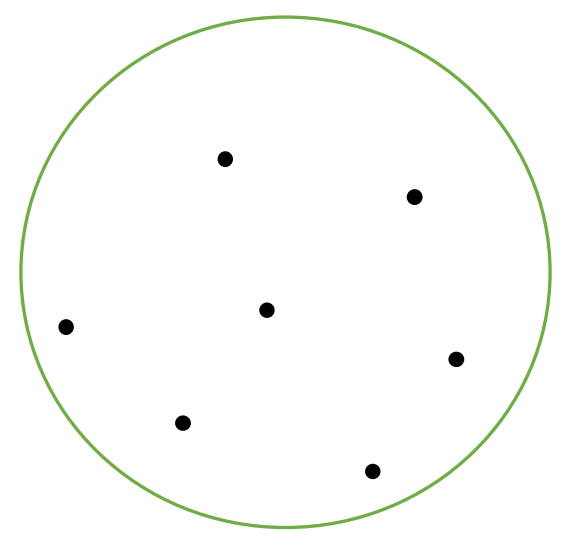

Fig 1: Document A

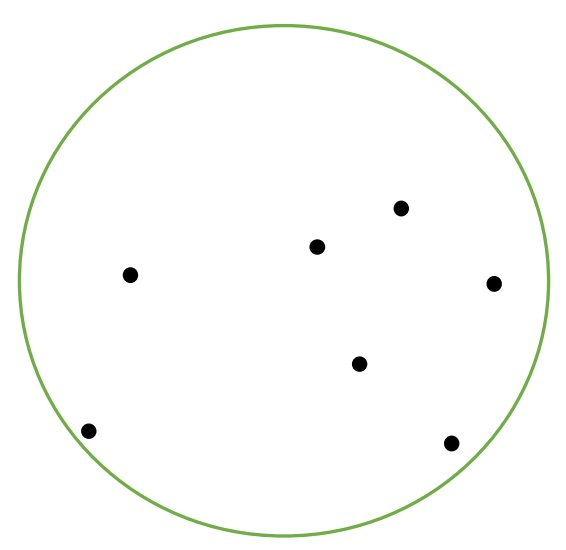

Fig 2: Document B

The dots in both the documents represent statements in the document. This statements are represented by functional words. A data pre-processing step is involved before generating document trees. After this, the documents are verified to check for common statements among the documents. Below is the figure that represents common statements between different documents. 


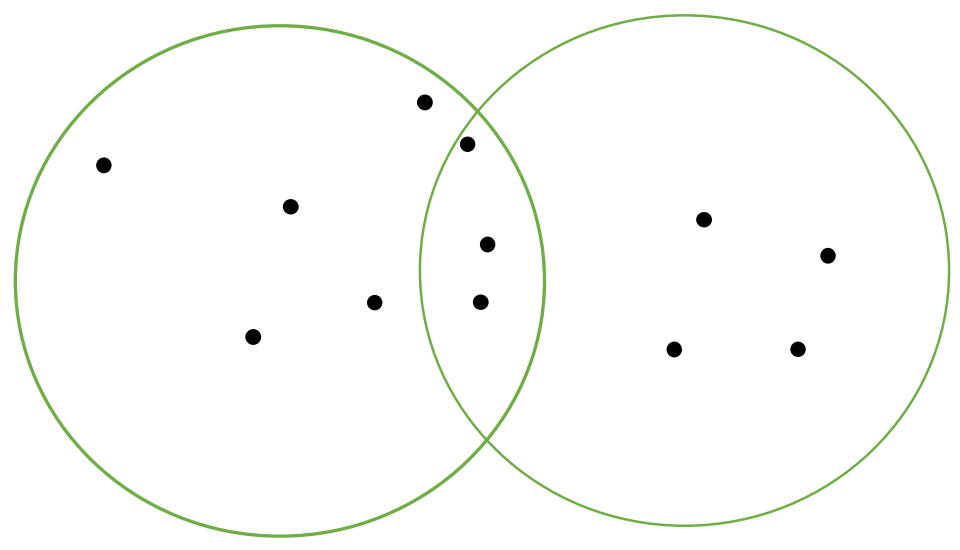

A

B

Fig 3: Identifying common statements

Total number of common statements $(\mathrm{A} \cap \mathrm{B})=3$

Total number of statement $(\mathrm{A} U \mathrm{~B})=13$

Jaccard Similarity $=(A \cap B) /(A \cup B)=3 / 13$. 
Now consider we have added a third document from same author.

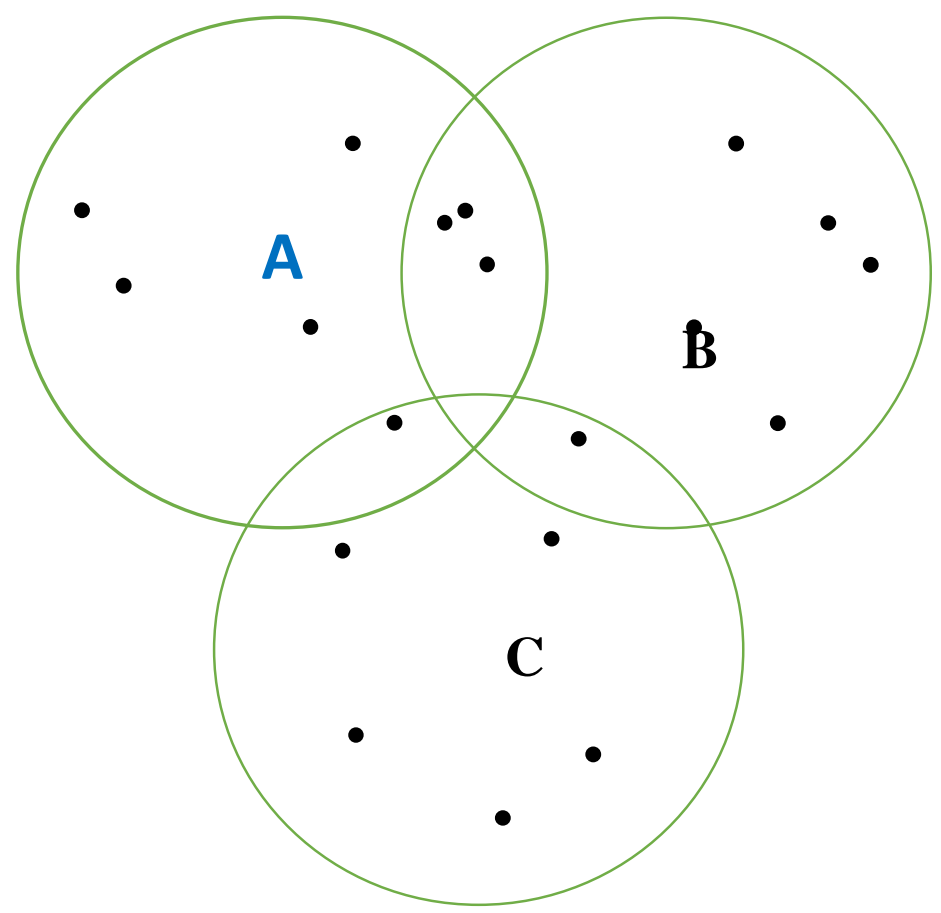

Fig 4: Set of three documents

Total number of statements in documents $=($ A U B U C $)=17$

Total number of common statements $=(\mathrm{A} \cap \mathrm{B})+(\mathrm{B} \cap \mathrm{C})+(\mathrm{A} \cap \mathrm{C})+(\mathrm{A} \cap \mathrm{B} \cap \mathrm{C})=6$

Jaccard Similarity $=(A \cap B)+(B \cap C)+(A \cap C)+(A \cap B \cap C) /(A \cup B U C)=6 / 17$

For improving the results, I have removed common statement in all the documents to improve the efficiency of the results. I did various trial to identify the minimum number of words in a statement. In the next page there are results for various variations in the minhash algorithm. 


\subsection{Results}

Test Case 1: In this test case, we consider sentence as a sentence. This sentence is converted to function word category and Algorithm is applied. Below are the results of comparison.

Test Document: J.K. Rowling - Harry Potter and the Order OF Phoenix.txt

\begin{tabular}{|c|c|c|}
\hline SI. No & Document name & \% Match \\
\hline 1 & Adam Smith - An Inquiry into the nature.txt & 8.212237094 \\
\hline 2 & Alexandre Dumas - The Count of Monte Cristo.txt & 7.661097852 \\
\hline 3 & $\begin{array}{l}\text { Arthur Conan Doyle -The Adventures of Sherlock } \\
\text { Holmes.txt }\end{array}$ & 17.06359592 \\
\hline 4 & Bram Stoker - Dracula.txt & 13.35579993 \\
\hline 5 & Canan Doyle - A Study in Scarlet.txt & 20.48085485 \\
\hline 6 & Charles Dickens - David Copperfield.txt & 9.639418152 \\
\hline 7 & Charlotte Bronte - Jane Eyre.txt & 14.95482205 \\
\hline 8 & Daniel Defoe - Robinson Crusoe.txt & 33.22515213 \\
\hline 9 & Dante Alighieri - The Divine Comedy.txt & 16.99772985 \\
\hline 10 & Edgar Rice Burroughs - A Princess of Mars.txt & 25.64102564 \\
\hline 11 & Elliott Whithey - The Pirate Shark.txt & 17.95523906 \\
\hline 12 & Frank Baum - The Wonderful Wizard of Oz.txt & 21.32564841 \\
\hline 13 & Friedrich Nietzsche - Beyond Good and Evil.txt & 32.5433526 \\
\hline 14 & Gabriel Garcia Marquez - 100 Years of Solitude.txt & 18.4086629 \\
\hline 15 & Harrison Williams - Legends of Loudoun.txt & 21.67042889 \\
\hline 16 & harrypotter1.txt & 100 \\
\hline 17 & harrypotter2.txt & 17.28748806 \\
\hline 18 & Herbert George Wells - The War of the Worlds.txt & 20.88959492 \\
\hline 19 & Herman Melville - Moby Dick.txt & 14.75980931 \\
\hline 20 & Herman See; y - A Son of the City.txt & 18.58648965 \\
\hline 21 & Hermann Hesse- Siddhartha.txt & 21.72264355 \\
\hline 22 & James Joyce - Dubliners.txt & 20.17746914 \\
\hline 23 & James Matthew Barrie - Peter Pan.txt & 22.35294118 \\
\hline 24 & Jane Austen - Emma.txt & 15.22994652 \\
\hline 25 & John Milton - Paradise Lost.txt & 26.67380825 \\
\hline 26 & Jonathan Swift - Gulivers Traveles.txt & 26.55977693 \\
\hline 27 & Joseph Conrad - Heart of Darkness.txt & 22.29199372 \\
\hline 28 & Jules Verne - Around the World in 80 Days.txt & 20.78720787 \\
\hline 29 & Julia Ward Howe - From the Oak to the Olive.txt & 16.00249066 \\
\hline 30 & Leo Tolstoy - War and Peace.txt & 6.379377685 \\
\hline
\end{tabular}

Table 3: Results for Jaccard Similarity for Test Case 1 
Test Case 2: In this test case, we consider a paragraph as a sentence. The word of the sentence is considered as symbol and Alergia Algorithm is applied. Below are the results of comparison.

Test Document: J.K. Rowling - Harry Potter and the Order OF Phoenix.txt

\begin{tabular}{|r|l|r|}
\hline SI. No & Document name & \% Match \\
\hline $\mathbf{1}$ & Adam Smith - An Inquiry into the nature.txt & 0 \\
\hline $\mathbf{2}$ & Alexandre Dumas - The Count of Monte Cristo.txt & 0.014160295 \\
\hline $\mathbf{3}$ & Arthur Conan Doyle -The Adventures of Sherlock & \\
\hline $\mathbf{4}$ & Bram Stoker - Dracula.txt & 0.039936102 \\
\hline $\mathbf{5}$ & Canan Doyle - A Study in Scarlet.txt & 0 \\
\hline $\mathbf{6}$ & Charles Dickens - David Copperfield.txt & 0 \\
\hline $\mathbf{7}$ & Charlotte Bronte - Jane Eyre.txt & 0 \\
\hline $\mathbf{8}$ & Daniel Defoe - Robinson Crusoe.txt & 0 \\
\hline $\mathbf{9}$ & Dante Alighieri - The Divine Comedy.txt & 0 \\
\hline $\mathbf{1 0}$ & Edgar Rice Burroughs - A Princess of Mars.txt & 0 \\
\hline $\mathbf{1 1}$ & Elliott Whithey - The Pirate Shark.txt & 0 \\
\hline $\mathbf{1 2}$ & Frank Baum - The Wonderful Wizard of Oz.txt & 0 \\
\hline $\mathbf{1 3}$ & Friedrich Nietzsche - Beyond Good and Evil.txt & 0 \\
\hline $\mathbf{1 4}$ & Gabriel Garcia Marquez - 100 Years of Solitude.txt & 0.054945055 \\
\hline $\mathbf{1 5}$ & Harrison Williams - Legends of Loudoun.txt & 0 \\
\hline $\mathbf{1 6}$ & harrypotter1.txt & 100 \\
\hline $\mathbf{1 7}$ & harrypotter2.txt & 0 \\
\hline $\mathbf{1 8}$ & Herbert George Wells - The War of the Worlds.txt & 0 \\
\hline $\mathbf{1 9}$ & Herman Melville - Moby Dick.txt & 0.116618076 \\
\hline $\mathbf{2 0}$ & Herman See;y - A Son of the City.txt & 0 \\
\hline $\mathbf{2 1}$ & Hermann Hesse- Siddhartha.txt & 0 \\
\hline $\mathbf{2 2}$ & James Joyce - Dubliners.txt & 0 \\
\hline $\mathbf{2 3}$ & James Matthew Barrie - Peter Pan.txt & 0 \\
\hline $\mathbf{2 4}$ & Jane Austen - Emma.txt & 0 \\
\hline $\mathbf{2 5}$ & John Milton - Paradise Lost.txt & 0 \\
\hline $\mathbf{2 6}$ & Jonathan Swift - Gulivers Traveles.txt & 0 \\
\hline $\mathbf{2 7}$ & Joseph Conrad - Heart of Darkness.txt & 0 \\
\hline $\mathbf{2 8}$ & Jules Verne - Around the World in 80 Days.txt & 0.057852 \\
\hline $\mathbf{2 9}$ & Julia Ward Howe - From the Oak to the Olive.txt & 0 \\
\hline $\mathbf{3 0}$ & Leo Tolstoy - War and Peace.txt & 0 \\
\hline & & 0 \\
\hline
\end{tabular}

Table 4: Results for Jaccard Similarity for Test Case 2 
Test Case 3: In this test case, we consider a paragraph as a sentence. These sentences are converted to functional word categories and Alergia Algorithm is applied. Below are the results of comparison.

Test Document: J.K. Rowling - Harry Potter and the Order OF Phoenix.txt

\begin{tabular}{|c|c|c|}
\hline Sl. No & Document name & \% Match \\
\hline 1 & Adam Smith - An Inquiry into the nature.txt & 34.1888176 \\
\hline 2 & Alexandre Dumas - The Count of Monte Cristo.txt & 15.31633617 \\
\hline 3 & $\begin{array}{l}\text { Arthur Conan Doyle -The Adventures of Sherlock } \\
\text { Holmes.txt }\end{array}$ & 47.65517241 \\
\hline 4 & Bram Stoker - Dracula.txt & 46.69163546 \\
\hline 5 & Canan Doyle - A Study in Scarlet.txt & 37.0332997 \\
\hline 6 & Charles Dickens - David Copperfield.txt & 26.54664484 \\
\hline 7 & Charlotte Bronte - Jane Eyre.txt & 32.60120586 \\
\hline 8 & Daniel Defoe - Robinson Crusoe.txt & 65 \\
\hline 9 & Dante Alighieri - The Divine Comedy.txt & 53.90702275 \\
\hline 10 & Edgar Rice Burroughs - A Princess of Mars.txt & 74.87487487 \\
\hline 11 & Elliott Whithey - The Pirate Shark.txt & 40.75587334 \\
\hline 12 & Frank Baum - The Wonderful Wizard of Oz.txt & 43.04029304 \\
\hline 13 & Friedrich Nietzsche - Beyond Good and Evil.txt & 16.66666667 \\
\hline 14 & Gabriel Garcia Marquez - 100 Years of Solitude.txt & 54.81727575 \\
\hline 15 & Harrison Williams - Legends of Loudoun.txt & 49.94571118 \\
\hline 16 & harrypotter1.txt & 100 \\
\hline 17 & harrypotter2.txt & 31.45961266 \\
\hline 18 & Herbert George Wells - The War of the Worlds.txt & 56.8788501 \\
\hline 19 & Herman Melville - Moby Dick.txt & 43.07159353 \\
\hline 20 & Herman See;y - A Son of the City.txt & 41.60331721 \\
\hline 21 & Hermann Hesse- Siddhartha.txt & 28.86266094 \\
\hline 22 & James Joyce - Dubliners.txt & 50.77343039 \\
\hline 23 & James Matthew Barrie - Peter Pan.txt & 40.97807757 \\
\hline 24 & Jane Austen - Emma.txt & 40.21864212 \\
\hline 25 & John Milton - Paradise Lost.txt & 26.53061224 \\
\hline 26 & Jonathan Swift - Gulivers Traveles.txt & 47.67063922 \\
\hline 27 & Joseph Conrad - Heart of Darkness.txt & 17.28395062 \\
\hline 28 & Jules Verne - Around the World in 80 Days.txt & 54.66786355 \\
\hline 29 & Julia Ward Howe - From the Oak to the Olive.txt & 39.51434879 \\
\hline 30 & Leo Tolstoy - War and Peace.txt & 11.36458478 \\
\hline
\end{tabular}

Table 5: Results for Jaccard Similarity for Test Case 3 


\section{Conclusion}

From the above results it can be observed that Jaccard Similarity doesn't give good matching results. In all the above 3 test cases, the results were negligible and doesn't follow any good pattern to come to proper conclusion. We can conclude that this method can't be used to identify the author of the document. 


\section{Applying Stochastic Finite Automata using Alergia Algorithm to}

\section{recognize author}

Below are the experimental results for a variety of Alpha values ranging from 0.1 to 0.95 by incrementing the value of alpha by 0.05

Test Case 1: In this test case, we consider sentence as a sentence. This sentence is converted to function word category and Alergia Algorithm is applied. Below are the results of comparison.

Test Document: J.K. Rowling - Harry Potter and the Order OF Phoenix.txt

\begin{tabular}{|c|c|c|c|c|c|c|c|c|c|c|c|c|c|c|c|c|}
\hline SI.No & Alpha & Doc01 & Doc02 & Doc03 & Doc04 & Doc05 & Doc06 & Doc07 & Doc08 & Doc9 & Doc10 & Doc11 & Doc12 & Doc13 & Doc14 & Doc15 \\
\hline 1 & 0.1 & 99.791 & 99.834 & 99.669 & 99.811 & 99.646 & 99.789 & 99.814 & 99.182 & 99.776 & 99.62 & 99.892 & 99.911 & 99.632 & 99.846 & 99.918 \\
\hline 2 & 0.15 & 91.378 & 95.587 & 96.856 & 97.227 & 96.743 & 96.692 & 95.974 & 82.74 & 95.842 & 90.702 & 98.886 & 97.294 & 93.33 & 93.251 & 96.2 \\
\hline 3 & 0.2 & 79.873 & 92.254 & 93.229 & 94.384 & 93.168 & 94.293 & 92.468 & 73.783 & 91.326 & 86.855 & 94.682 & 91.571 & 81.933 & 87.89 & 89.311 \\
\hline 4 & 0.25 & 78.488 & 92.642 & 93.629 & 93.41 & 93.097 & 92.773 & 91.439 & 66.38 & 91.482 & 84.108 & 96.083 & 92.236 & 82.458 & 86.348 & 91.006 \\
\hline 5 & 0.3 & 74.839 & 91.001 & 92.857 & 91.442 & 92.425 & 92.281 & 90.502 & 67.239 & 85.245 & 82.164 & 94.43 & 90.284 & 77.994 & 86.83 & 88.218 \\
\hline 6 & 0.35 & 77.652 & 93.499 & 94.098 & 93.718 & 93.947 & 93.608 & 93.331 & 68.262 & 91.08 & 86.56 & 96.299 & 91.659 & 82.09 & 87.91 & 90.623 \\
\hline 7 & 0.4 & 59.981 & 86.459 & 88.555 & 86.443 & 89.062 & 85.318 & 84.936 & 40.532 & 77.867 & 67.16 & 91.197 & 3.718 & 65.389 & 8.415 & 5.545 \\
\hline 8 & 0.45 & 44.896 & 78.746 & 80.323 & 75.42 & 78.372 & 77.186 & 76.078 & 30.92 & 67.27 & 54.522 & 86.238 & 74.889 & 54.307 & 57.809 & 70.886 \\
\hline 9 & 0.5 & 39.052 & 75.164 & 78.737 & 74.903 & 76.354 & 75.384 & 72.35 & 27.853 & 61.569 & 48.648 & 85.411 & 70.763 & 50.945 & 54.435 & 66.594 \\
\hline 10 & 0.55 & 41.7 & 78.461 & 81.509 & 78.442 & 79.788 & 78.82 & 76.885 & 31.943 & 66.644 & 53.931 & 86.921 & 73.957 & 54.044 & 59.969 & 68.972 \\
\hline 11 & 0.6 & 32.834 & 72.112 & 74.214 & 70.41 & 71.186 & 72.7 & 69.511 & 23.845 & 56.919 & 43.068 & 80.704 & 66.327 & 45.693 & 49.73 & 62.575 \\
\hline 12 & 0.65 & 29.498 & 71.188 & 73.525 & 68.84 & 70.372 & 71.852 & 69.149 & 24.049 & 56.003 & 41.082 & 79.806 & 66.105 & 45.221 & 47.532 & 60.361 \\
\hline 13 & 0.7 & 23.306 & 66.439 & 69.719 & 63.373 & 65.062 & 916 & 6 & 91 & 49 & 84 & 22 & 17 & 99 & 287 & .561 \\
\hline 14 & 0.75 & 17.07 & 58.678 & 61.473 & 53.394 & 55.823 & 61.242 & 55.858 & 16.933 & 39.347 & 25.106 & 69.206 & 50.665 & 34.559 & 35.017 & 51.258 \\
\hline 15 & 0.8 & 16.713 & 58.238 & 59.68 & 51.526 & 53.77 & 60.061 & 56.145 & 16.728 & 38.006 & 23.838 & 67.481 & 48.625 & 35.137 & 33.378 & 50.273 \\
\hline 16 & 0.85 & 15.137 & 56.763 & 58.977 & 50.184 & 52.425 & 59.085 & 54.244 & 15.91 & 36.15 & 24.26 & 66.439 & 45.963 & 32.878 & 32.356 & 49.563 \\
\hline 17 & 0.9 & 13.369 & 54.032 & 55.736 & 46.804 & 50.867 & 56.766 & 52.045 & 15.91 & 32.238 & 21.682 & 63.852 & 42.325 & 2.353 & 29.136 & 47.048 \\
\hline 18 & 0.95 & 12.393 & 50.972 & 52.592 & 44.121 & 46.938 & 54.433 & 48.817 & 14.233 & 30.025 & 19.949 & 60.87 & 40.151 & 30.252 & 27.902 & 45.927 \\
\hline
\end{tabular}




\begin{tabular}{|c|c|c|c|c|c|c|c|c|c|c|c|c|c|c|c|c|}
\hline SI.No & Alpha & Doc16 & Doc17 & Doc18 & Doc19 & Doc20 & Doc21 & Doc22 & Doc23 & Doc24 & Doc25 & Doc26 & Doc27 & Doc28 & Doc29 & Doc30 \\
\hline 1 & 0.1 & 100 & 99.882 & 99.91 & 99.806 & 99.949 & 99.839 & 99.908 & 99.789 & 99.77 & 99.688 & 99.688 & 99.842 & 99.901 & 99.954 & 99.851 \\
\hline 2 & 0.15 & 100 & 99.197 & 97.164 & 95.787 & 98.443 & 94.675 & 98.384 & 98.193 & 97.969 & 92.15 & 87.296 & 97.825 & 97.618 & 95.861 & 97.194 \\
\hline 3 & 0.2 & 100 & 97.59 & 91.071 & 90.382 & 96.766 & 89.403 & 96.896 & 94.096 & 93.85 & 85.483 & 81.291 & 93.278 & 93.5 & 90.22 & 93.436 \\
\hline 4 & 0.25 & 100 & 97.815 & 93.575 & 91.127 & 97.091 & 89.779 & 96.381 & 94.639 & 92.26 & 83.614 & 76.362 & 93.99 & 95.014 & 92.277 & 93.767 \\
\hline 5 & 0.3 & 100 & 96.841 & 91.976 & 87.176 & 95.756 & 85.745 & 95.463 & 94.036 & 91.436 & 73.956 & 75.668 & 92.962 & 93.203 & 88.809 & 91.984 \\
\hline 6 & 0.35 & 100 & 97.751 & 92.881 & 0.74 & 96.629 & 91.555 & 96.675 & 94.217 & 92.633 & 82.617 & 79.104 & 93.99 & 95.361 & 92.671 & 93.974 \\
\hline 7 & 0.4 & 100 & 95.277 & 83.71 & 80.744 & 93.515 & 81.119 & 93.148 & 89.337 & 87.125 & 53.707 & 56.022 & 87.9 & 8.787 & 86.15 & 85.971 \\
\hline 8 & 0.45 & 100 & 91.315 & 76.893 & 72.888 & 89.973 & 71.867 & 86.976 & 81.386 & 79.184 & 43.863 & 44.186 & 80.467 & 82.039 & 77.896 & 78.271 \\
\hline 9 & 0.5 & 100 & 90.587 & 74.811 & 70.002 & 87.953 & 66.541 & 86.315 & 79.006 & 76.32 & 42.555 & 39.327 & 79.992 & 79.558 & 74.243 & 76.464 \\
\hline 10 & 0.55 & 100 & 92.086 & 75.716 & 71.658 & 89.63 & 72.727 & 88.134 & 82.169 & 79.174 & 45.296 & 43.457 & 81.257 & 83.032 & 75.861 & 79.693 \\
\hline 11 & 0.6 & 100 & 87.717 & 68.477 & 65.798 & 85.489 & 63.206 & 83.229 & 76.024 & 73.455 & 37.009 & 35.127 & 75.603 & 75.862 & 68.231 & 72.38 \\
\hline 12 & 0.65 & 100 & 87.92 & 67.722 & 64.8 & 84.326 & 61.592 & 83.321 & 76.476 & 73.273 & 35.576 & 30.719 & 74.614 & 74.671 & 67.145 & 71.573 \\
\hline 13 & 0.7 & 100 & 84.547 & 61.719 & 9.58 & 81.828 & 6.59 & 78.325 & 71.265 & 68.426 & 29.533 & 26.449 & 70.621 & 69.685 & 58.497 & 67.085 \\
\hline 14 & 0.75 & 100 & 78.786 & 51.855 & 53.845 & 75.205 & 47.768 & 70.757 & 63.735 & 61.165 & 26.044 & 20.132 & 61.17 & 62.516 & 49.225 & 59.513 \\
\hline 15 & 0.8 & 100 & 77.918 & 50.498 & 52.208 & 74.196 & 45.939 & 70.261 & 62.259 & 59.747 & 23.738 & 19.715 & 61.329 & 61.871 & 47.376 & 58.454 \\
\hline 16 & 0.85 & 100 & 77.318 & 50.226 & 51 & 73.101 & 01 & 69.453 & 61. & 91 & 576 & 9.16 & 568 & 705 & .087 & 57.133 \\
\hline 17 & 0.9 & 100 & 73.463 & 52 & 49.429 & 69.713 & 174 & 65.209 & 8.554 & 925 & 555 & 696 & 56.781 & .462 & .486 & 4.002 \\
\hline 18 & 0.95 & 100 & 71.375 & 44.585 & 47.365 & 68.036 & 39.699 & 63.281 & 55.663 & 53.214 & 20.249 & 15.238 & 53.341 & 55.296 & 38.89 & 51.592 \\
\hline
\end{tabular}

Table 6: Representing Alergia results for Test Case 1

Test Case 2: In this test case, we consider a paragraph as a sentence. The word of the sentence is

considered as symbol and Alergia Algorithm is applied. Below are the results of comparison.

Test Document: J.K. Rowling - Harry Potter and the Order OF Phoenix.txt

\begin{tabular}{|c|c|c|c|c|c|c|c|c|c|c|c|c|c|c|c|c|}
\hline SI.No & Alpha & Doc01 & Doc02 & Doc03 & Doc04 & Doc05 & Doc06 & Doc07 & Doc08 & Doc9 & Doc10 & Doc11 & Doc12 & Doc13 & Doc14 & Doc15 \\
\hline 1 & 0.1 & 0.048 & 0 & 0 & 0 & 0 & 0 & 0 & 0.157 & 0.145 & 0.114 & 0.186 & 0 & 0.426 & 0 & 0.173 \\
\hline 2 & 0.15 & 0.048 & 0 & 0 & 0 & 0 & 0 & 0 & 0.157 & 0.145 & 0.114 & 0.186 & 0 & 0.426 & 0 & 0.173 \\
\hline 3 & 0.2 & 0.048 & 0 & 0 & 0 & 0 & 0 & 0 & 0.157 & 0.145 & 0.114 & 0.186 & 0 & 0.426 & 0 & 0.173 \\
\hline 4 & 0.25 & 0.048 & 0 & 0 & 0 & 0 & 0 & 0 & 0.157 & 0.145 & 0.114 & 0.186 & 0 & 0.426 & 0 & 0.173 \\
\hline 5 & 0.3 & 0.048 & 0 & 0 & 0 & 0 & 0 & 0 & 0.157 & 0.145 & 0.114 & 0.186 & 0 & 0.426 & 0 & 0.173 \\
\hline 6 & 0.35 & 0.048 & 0 & 0 & 0 & 0 & 0 & 0 & 0.157 & 0.145 & 0.114 & 0.186 & 0 & 0.426 & 0 & 0.173 \\
\hline 7 & 0.4 & 0.048 & 0 & 0 & 0 & 0 & 0 & 0 & 0.157 & 0.145 & 0.114 & 0.186 & 0 & 0.426 & 0 & 0.173 \\
\hline 8 & 0.45 & 0.048 & 0 & 0 & 0 & 0 & 0 & 0 & 0.157 & 0.145 & 0.114 & 0.186 & 0 & 0.426 & 0 & 0.173 \\
\hline 9 & 0.5 & 0.048 & 0 & 0 & 0 & 0 & 0 & 0 & 0.157 & 0.145 & 0.114 & 0.186 & 0 & 0.426 & 0 & 0.173 \\
\hline 10 & 0.55 & 0.048 & 0 & 0 & 0 & 0 & 0 & 0 & 0.157 & 0.145 & 0.114 & 0.186 & 0 & 0.426 & 0 & 0.173 \\
\hline 11 & 0.6 & 0.048 & 0 & 0 & 0 & 0 & 0 & 0 & 0.157 & 0.145 & 0.114 & 0.186 & 0 & 0.426 & 0 & 0.173 \\
\hline 12 & 0.65 & 0.048 & 0 & 0 & 0 & 0 & 0 & 0 & 0.157 & 0.145 & 0.114 & 0.186 & 0 & 0.426 & 0 & 0.173 \\
\hline 13 & 0.7 & 0.048 & 0 & 0 & 0 & 0 & 0 & 0 & 0.157 & 0.145 & 0.114 & 0.186 & 0 & 0.426 & 0 & 0.173 \\
\hline 14 & 0.75 & 0.048 & 0 & 0 & 0 & 0 & 0 & 0 & 0.157 & 0.145 & 0.114 & 0.186 & 0 & 0.426 & 0 & 0.173 \\
\hline 15 & 0.8 & 0.048 & 0 & 0 & 0 & 0 & 0 & 0 & 0.157 & 0.145 & 0.114 & 0.186 & 0 & 0.426 & 0 & 0.173 \\
\hline 16 & 0.85 & 0.048 & 0 & 0 & 0 & 0 & 0 & 0 & 0.157 & 0.145 & 0.114 & 0.186 & 0 & 0.426 & 0 & 0.173 \\
\hline 17 & 0.9 & 0.048 & 0 & 0 & 0 & 0 & 0 & 0 & 0.157 & 0.145 & 0.114 & 0.186 & 0 & 0.426 & 0 & 0.173 \\
\hline 18 & 0.95 & 0.048 & 0 & 0 & 0 & 0 & 0 & 0 & 0.157 & 0.145 & 0.114 & 0.186 & 0 & 0.426 & 0 & 0.173 \\
\hline
\end{tabular}




\begin{tabular}{|c|c|c|c|c|c|c|c|c|c|c|c|c|c|c|}
\hline SI.No & Alpha & Doc16 & Doc17 & Doc18 & Doc19 & Doc20 & Doc21 & Doc22 & Doc23 & Doc24 & Doc25 & Doc26 & Doc27 & Doc28 \\
\hline 1 & 0.1 & 0 & 0.059 & 0 & 0.295 & 0.11 & 0 & 0 & 0 & 0.204 & 0.625 & 0 & 0 & 0.013 \\
\hline 2 & 0.15 & 0 & 0.059 & 0 & 0.295 & 0.11 & 0 & 0 & 0 & 0.204 & 0.625 & 0 & 0 & 0.013 \\
\hline 3 & 0.2 & 0 & 0.059 & 0 & 0.295 & 0.11 & 0 & 0 & 0 & 0.204 & 0.625 & 0 & 0 & 0.013 \\
\hline 4 & 0.25 & 0 & 0.059 & 0 & 0.295 & 0.11 & 0 & 0 & 0 & 0.204 & 0.625 & 0 & 0 & 0.013 \\
\hline 5 & 0.3 & 0 & 0.059 & 0 & 0.295 & 0.11 & 0 & 0 & 0 & 0.204 & 0.625 & 0 & 0 & 0.013 \\
\hline 6 & 0.35 & 0 & 0.059 & 0 & 0.295 & 0.11 & 0 & 0 & 0 & 0.204 & 0.625 & 0 & 0 & 0.013 \\
\hline 7 & 0.4 & 0 & 0.059 & 0 & 0.295 & 0.11 & 0 & 0 & 0 & 0.204 & 0.625 & 0 & 0 & 0.013 \\
\hline 8 & 0.45 & 0 & 0.059 & 0 & 0.295 & 0.11 & 0 & 0 & 0 & 0.204 & 0.625 & 0 & 0 & 0.013 \\
\hline 9 & 0.5 & 0 & 0.059 & 0 & 0.295 & 0.11 & 0 & 0 & 0 & 0.204 & 0.625 & 0 & 0 & 0.013 \\
\hline 10 & 0.55 & 0 & 0.059 & 0 & 0.295 & 0.11 & 0 & 0 & 0 & 0.204 & 0.625 & 0 & 0 & 0.013 \\
\hline 11 & 0.6 & 0 & 0.059 & 0 & 0.295 & 0.11 & 0 & 0 & 0 & 0.204 & 0.625 & 0 & 0 & 0.013 \\
\hline 12 & 0.65 & 0 & 0.059 & 0 & 0.295 & 0.11 & 0 & 0 & 0 & 0.204 & 0.625 & 0 & 0 & 0.013 \\
\hline 13 & 0.7 & 0 & 0.059 & 0 & 0.295 & 0.11 & 0 & 0 & 0 & 0.204 & 0.625 & 0 & 0 & 0.013 \\
\hline 14 & 0.75 & 0 & 0.059 & 0 & 0.295 & 0.11 & 0 & 0 & 0 & 0.204 & 0.625 & 0 & 0 & 0.013 \\
\hline 15 & 0.8 & 0 & 0.059 & 0 & 0.295 & 0.11 & 0 & 0 & 0 & 0.204 & 0.625 & 0 & 0 & 0.013 \\
\hline 16 & 0.85 & 0 & 0.059 & 0 & 0.295 & 0.11 & 0 & 0 & 0 & 0.204 & 0.625 & 0 & 0 & 0.013 \\
\hline 17 & 0.9 & 0 & 0.059 & 0 & 0.295 & 0.11 & 0 & 0 & 0 & 0.204 & 0.625 & 0 & 0 & 0.013 \\
\hline 18 & 0.95 & 0 & 0.059 & 0 & 0.295 & 0.11 & 0 & 0 & 0 & 0.204 & 0.625 & 0 & 0 & 0.013 \\
\hline
\end{tabular}

Table 7: Representing Alergia results for Test Case 2

Test Case 3: In this test case, we consider a paragraph as a sentence. These sentences are converted to functional word categories and Alergia Algorithm is applied. Below are the results of comparison.

Test Document: J.K. Rowling - Harry Potter and the Order OF Phoenix.txt

\begin{tabular}{|c|c|c|c|c|c|c|c|c|c|c|c|c|c|c|c|c|}
\hline SI.No & Alpha & Doc01 & Doc02 & Doc03 & oc04 & Doc05 & Doc06 & oc07 & Doc08 & Doc9 & oc10 & Doc11 & Doc12 & oc13 & Doc14 & Doc15 \\
\hline 1 & 0.1 & 99.519 & 99.754 & 9.719 & 9.605 & 99.607 & 99.514 & 9.793 & 99.215 & 98.547 & 99.657 & 99.628 & 100 & 98.298 & 99.426 & 99.655 \\
\hline 2 & 15 & 97.448 & 98.492 & 98.172 & 5.455 & 95.874 & 96.079 & 98.263 & 91.523 & 96.948 & 98.398 & 3.138 & 98.584 & 6.17 & 1.073 & 98.791 \\
\hline 3 & 0.2 & 77.805 & 96.165 & 95.077 & 90.711 & 92.731 & 89.663 & 94.582 & 82.575 & 87.936 & 95.195 & 95.903 & 96.884 & 81.702 & 83.365 & 90.674 \\
\hline 4 & 0.25 & 57.342 & 90.118 & 87.693 & 84.321 & 87.23 & 79.909 & 87.676 & 63.265 & 79.215 & 88.558 & 90.317 & 93.768 & 65.957 & 64.054 & 74.266 \\
\hline 5 & 0.3 & 41.839 & 75.418 & 69.409 & 58.564 & 67.191 & 55.412 & 70.389 & 32.339 & 56.977 & 71.167 & 80.074 & 74.079 & 55.319 & 39.197 & 64.076 \\
\hline 6 & 0.35 & 11.796 & 42.822 & 33.966 & 20.619 & 32.22 & 17.272 & 34.326 & 8.006 & 22.384 & 21.854 & 38.92 & 37.394 & 33.617 & 9.751 & 25.734 \\
\hline 7 & 0.4 & 14.636 & 53.458 & 47.257 & 1.555 & 41.847 & 26.539 & 44.789 & 10.832 & 25.872 & 0.847 & 45.81 & 51.133 & 0.426 & 15.679 & 34.37 \\
\hline 8 & 0.45 & 3.274 & 26.811 & 1.73 & 11.067 & 13.556 & 745 & 1.05 & 256 & 849 & 5.95 & 15.829 & 1.448 & .426 & 4.015 & 17.271 \\
\hline 9 & 0.5 & 9.677 & 41.396 & 35.865 & 19.697 & 30.452 & 16.008 & 34.202 & 5.181 & 19.477 & 20.595 & 34.637 & 36.261 & 34.043 & 9.369 & 26.598 \\
\hline 10 & 0.55 & 6.211 & 32.825 & 27.496 & 11.989 & 21.415 & .754 & 25.31 & 297 & 12.064 & 11.67 & 22.16 & 26.771 & 28.085 & 6.501 & 20.035 \\
\hline 11 & 0.6 & 2.215 & .01 & 15.893 & 599 & 448 & 476 & 13.275 & 942 & 651 & 3.89 & 12.477 & 10.765 & 15.319 & 3.442 & 14.162 \\
\hline 12 & 0.65 & 4.574 & 30.121 & 24.473 & 11.331 & 18.468 & 10.078 & 23.863 & 2.669 & 9.884 & 10.297 & 18.994 & 23.654 & 20.426 & 5.354 & 17.789 \\
\hline 13 & 0.7 & 2.696 & 18.928 & 14.909 & 4.809 & 11.395 & 4.439 & 12.283 & 0.628 & 4.215 & 3.318 & 11.546 & 9.49 & 14.043 & 2.486 & 13.299 \\
\hline
\end{tabular}




\begin{tabular}{|c|c|c|c|c|c|c|c|c|c|c|c|c|c|c|c|c|c|}
\hline 14 & 0.75 & 2.215 & 21.712 & 15.208 & 11.603 & 3.755 & 8.251 & 3.986 & 10.008 & 0.628 & 3.779 & 2.746 & 8.194 & 7.082 & 10.213 & 2.486 & 13.817 \\
\hline 15 & 0.8 & 2.311 & 23.222 & 16.47 & 13.08 & 4.809 & 9.43 & 4.861 & 11.828 & 0.942 & 4.506 & 4.233 & 11.173 & 9.065 & 11.489 & 3.059 & 15.026 \\
\hline 16 & 0.85 & 1.926 & 19.132 & 13.389 & 10.408 & 3.821 & 5.894 & 3.467 & 8.809 & 0.628 & 2.762 & 3.089 & 9.125 & 6.374 & 10.638 & 1.53 & 13.99 \\
\hline 17 & 0.9 & 0.818 & 13.342 & 7.932 & 6.048 & 2.24 & 4.912 & 2.171 & 5.418 & 0.628 & 1.744 & 1.487 & 3.724 & 3.258 & 4.255 & 1.53 & 11.917 \\
\hline 18 & 0.95 & 1.348 & 13.531 & 8.538 & 5.696 & 2.569 & 3.929 & 2.041 & 5.376 & 0.628 & 1.308 & 0.572 & 4.283 & 3.399 & 5.532 & 1.912 & 11.917 \\
\hline
\end{tabular}

\begin{tabular}{|c|c|c|c|c|c|c|c|c|c|c|c|c|c|c|c|c|}
\hline SI.No & Alpha & Doc16 & Doc17 & Doc18 & Doc19 & Doc20 & Doc21 & Doc22 & Doc23 & Doc24 & Doc25 & Doc26 & Doc27 & Doc28 & Doc29 & Doc30 \\
\hline 1 & 0.1 & 100 & 99.914 & 99.851 & 99.524 & 99.852 & 99.705 & 99.45 & 99.79 & 99.814 & 99.353 & 98.569 & 98.125 & 100 & 99.482 & 99.796 \\
\hline 2 & 0.15 & 100 & 99.183 & 99.552 & 97.741 & 99.113 & 97.345 & 98.02 & 98.952 & 97.585 & 94.175 & 91.82 & 93.75 & 98.762 & 96.891 & 98.739 \\
\hline 3 & 0.2 & 100 & 98.023 & 95.224 & 87.277 & 97.044 & 92.625 & 94.169 & 98.008 & 92.26 & 74.434 & 77.505 & 81.875 & 96.078 & 83.679 & 95.071 \\
\hline 4 & 0.25 & 100 & 95.316 & 86.269 & 78.478 & 93.422 & 83.776 & 90.429 & 92.977 & 84.087 & 70.55 & 63.804 & 66.875 & 88.545 & 69.948 & 89.786 \\
\hline 5 & 0.3 & 100 & 84.186 & 68.06 & 61.534 & 84.479 & 63.422 & 72.607 & 79.14 & 59.133 & 49.191 & 40.082 & 43.75 & 78.844 & 43.523 & 76.159 \\
\hline 6 & 0.35 & 100 & 59.132 & 27.164 & 24.732 & 53.511 & 23.599 & 44.994 & 51.992 & 23.777 & 21.359 & 12.679 & 9.375 & 43.963 & 10.104 & 42.091 \\
\hline 7 & 0.4 & 100 & 65.234 & 42.388 & 31.748 & 62.158 & 36.578 & 49.835 & 60.168 & 32.941 & 21.036 & 19.632 & 20.625 & 57.069 & 14.249 & 52.292 \\
\hline 8 & 0.45 & 100 & 34.207 & 10 & 10.523 & 26.755 & 9.44 & 27.393 & 34.172 & 12.817 & 9.709 & 3.885 & 1.875 & 24.149 & 3.886 & 20.899 \\
\hline 9 & 0.5 & 100 & 55.952 & 24.03 & 23.722 & 49.446 & 21.239 & 41.694 & 50.629 & 24.272 & 14.563 & 11.043 & 10.625 & 43.653 & 8.549 & 40.448 \\
\hline 10 & 0.55 & 100 & 42.931 & 15.075 & 15.101 & 35.255 & 17.109 & 33.333 & 40.042 & 16.471 & 12.298 & 7.975 & 3.125 & 31.992 & 4.922 & 29.215 \\
\hline 11 & 0.6 & 100 & 25.698 & 6.119 & 7.313 & 20.547 & 9.44 & 21.012 & 26.31 & 6.687 & 6.149 & 3.067 & 1.875 & 18.473 & 2.332 & 15.27 \\
\hline 12 & 0.65 & 100 & 39.837 & 14.478 & 13.139 & 35.255 & 13.274 & 32.013 & 36.268 & 13.251 & 8.091 & 6.953 & .125 & 29.205 & 4.922 & 26.707 \\
\hline 13 & 0.7 & 100 & 23.893 & 6.269 & 6.659 & 18.477 & 8.26 & 18.702 & 22.956 & 6.006 & 4.531 & 3.272 & 1.875 & 19.917 & 2.85 & 13.869 \\
\hline 14 & 0.75 & 100 & 19.424 & 6.269 & 5.945 & 16.334 & 8.555 & 15.512 & 17.82 & 5.201 & 5.825 & 3.272 & 0.625 & 14.861 & 2.85 & 11.768 \\
\hline 15 & 0.8 & 100 & 22.303 & 7.164 & 7.372 & 18.551 & 9.145 & 16.942 & 21.384 & 5.882 & 5.825 & 3.681 & 0.625 & 14.964 & 2.591 & 13.029 \\
\hline 16 & 0.85 & 100 & 18.049 & 4.925 & 5.351 & 14.265 & 4.72 & 14.411 & 18.658 & 4.334 & 5.502 & 1.431 & 1.25 & 13.209 & 2.85 & 10.596 \\
\hline 17 & 0.9 & 100 & 10.786 & 2.687 & 3.805 & 8.278 & 4.13 & 8.691 & 10.901 & 1.981 & 3.56 & 2.045 & 625 & .772 & 2.073 & 5.489 \\
\hline 18 & 0.95 & 100 & 11.818 & 2.985 & 3.032 & 9.387 & 3.54 & 9.351 & 10.692 & 2.477 & 3.56 & 1.636 & 0.625 & 7.637 & 1.554 & 5.884 \\
\hline
\end{tabular}

Table 8: Representing Alergia results for Test Case 3

\section{Conclusion:}

From the above test cases, we can say that Test case 2 doesn't make much sense for converting whole sentence into a paragraph and considering all the possible words. But Test case 1 and 3 does make sense as we shorten the paragraph by function words and which gives good results in identifying documents written by similar author. 


\section{Future Work}

I would like to test this in cloud environment implementing the concept of computing grids or in big data environment. Also including various text processing techniques like stemming and lemmatization. I would also like to test this application with other algorithms like Alergia. This application might also be helpful to identify plagiarism.

\section{Conclusion}

Automata with Alergia builds a transition tree which represents the writing pattern of an author. This mechanism helps to identify the similarity between the documents. Based on this similarity we can determine the original author of a document with the \% match. If the document size is too small the results may not be accurate but, as the document size increases there is high possibility that automata will give accurate result. Furthermore, this algorithm also helps to determine plagiarized content of a document. Using this algorithm, we were able to determine that harry potter author was recognized and the $\%$ match with the document is high. So, use of Alergia algorithm does a good job of recognizing author of the document by developing the author writing pattern.

Where as in the experiment 2 using Jaccard similarity, which doesn't develop author writing pattern, but it does a good job of calculating distance between sentences. According to the initial ideology and assumptions, this result was supposed to show good match with similarity author. But, the results where negative based on the calculating distance between the sentences. 
So, based on the above conclusion we can derive that experiment 2 using Jaccard Similarity can't be used for recognizing authors pattern and Automata with Alergia can be used for recognizing similarity between the documents and author. 


\section{References}

1. Slaney, M ; Yahoo! Research, Sunnyvale, CA , USA ; Lifshits, Y. ; Junfeng He “Optimal Parameters for Locality-Sensitive Hashing 2012”

2. Locality Sensitive Hashing: https://en.wikipedia.org/wiki/Locality-sensitive_hashing

3. Oprisa, C. "A MinHash Approach for Clustering Large Collections of Binary Programs", Control Systems and Computer Science (CSCS), 2015 20th International Conference on, On page(s): $157-163$

4. Oprisa, C.; Checiches, M.; Nandrean, A. "Locality-sensitive hashing optimizations for fast malware clustering", Intelligent Computer Communication and Processing (ICCP), 2014 IEEE International Conference on, On page(s): 97 - 104

5. Rajaraman, A.; Ullman, J. (2010). "Mining of Massive Datasets, Ch. 3.".

6. Gionis, A.; Indyk, P.; Motwani, R. (1999). "Similarity Search in High Dimensions via Hashing". Proceedings of the 25th Very Large Database (VLDB) Conference.

7. Indyk, Piotr.; Motwani, Rajeev. (1998). "Approximate Nearest Neighbors: Towards Removing the Curse of Dimensionality.". Proceedings of 30th Symposium on Theory of Computing.

8. Function Words : https://en.wikipedia.org/wiki/Function_word

9. Wikipedia: https://en.wikipedia.org/wiki/Wikipedia

10. Wikipedia Dataset: http://wiki.dbpedia.org/Datasets

11. Josh Levs, CNN: J.K. Rowling revealed as secret author of crime novel, http://www.cnn.com/2013/07/14/world/rowling-secret-book/

12. Hamming Distance: https://en.wikipedia.org/wiki/Hamming_distance

13. Rajeev Motwani, Jeffrey D. Ullman, John E. Hopcroft.: Introduction to Automata Theory, Languages, And Computation (2003) 
14. Jir Poner, Filip Lanka.: Computational Studies of RNA and DNA. Challenges and Advances in Computational Chemestry and Physics (2006)

15. Ferdinand Wagner, Ruedi Schmuki, Thomas Wagner, Peter Wolstenholme.: Modeling Software with Finite State Machines: A Practical Approach (2006)

16. Min Hashing: https://en.wikipedia.org/wiki/MinHash 